\title{
CRGOURMETCOFFEE.COM: USING E-COMMERCE TO MITIGATE THE COFFEE PARADOX IN COSTA RICA
}

\author{
Francisco J. Mata ${ }^{1}$ and Irene Hernández Ruiz ${ }^{2}$ \\ Escuela de Informática, Universidad Nacional-Costa Rica, Heredia, Costa Rica
}

\begin{abstract}
We present the background and the design and development considerations for an electronic platform to sell Costa Rican roasted coffee through e-commerce, referred to as crgourmetcoffee.com (https://www.crgourmetcoffee.com). This system is proposed as a solution to mitigate the coffee paradox - phenomenon that makes the coffee prices received by famers in developing countries to be increasingly lower, despite a growing demand for this product. In this regard, crgourmetcoffee.com is aimed at enabling Costa Rican coffee farmers to sell directly its coffee to final consumers in developed countries, eliminating intermediaries in an effort to allow producers to obtain higher price margins.
\end{abstract}

\section{KEYWORDS}

E-commerce, Coffee, Costa Rica, Coffee Paradox

\section{INTRODUCTION}

Costa Rica began producing coffee since the XIX century. Until the decade of 1970, the country's economy heavily depended on this product; however, the economic importance of coffee has diminished over time - giving way to other agricultural products like banana and pineapple and to medical devices. According to the Costa Rican Export Promoting Agency PROCOMER (2017), coffee exports represented 3 percent of total exports of the country, in economic terms, for 2017.

Coffee, like most agricultural products that are distributed through agro-chains, is at the mercy of fluctuations in international markets. As explained by Daviron and Ponte (2005), these fluctuations - evidenced in the form of large variations in prices- affect mainly the producers of this product, which are characterized by being small farmers located in developing countries. These authors refer to this phenomenon to as the coffee paradox. This situation is a major factor for the continuous decrease of coffee producers in Costa Rica. In the last decade, this number has decreased in more than 10 thousand producers, from 53,086 (2006-2007 harvest) to 43,035 (2016-2017 harvest) (ICAFE, 2017).

As a result of this condition, many lands with coffee vocation in the country are becoming properties for real estate developments. This is notorious in several parts of the Central Valley -where most of the country's population is concentrated. Likewise, knowledge for coffee production -traditionally passed down from generation to generation- is being lost.

On the other hand, Costa Rican coffee continues to be recognized for its quality worldwide. In the 2018 edition of the Cup of Excellence (https://allianceforcoffeeexcellence.org/cup-of-excellence/) -competition held in several countries to reward coffee quality-, one of the participating coffee samples in Costa Rica reached the extraordinary price of US\$300.09 per pound in the auction held as part of this international competition. This price exceeded the record of US $\$ 130.20$ per pound, previously obtained in 2017 by Brazil in this same competition. As a reference, the price of coffee in 2018 in the international market was just US\$1.15 per pound (Otey, 2018).

\footnotetext{
fmata@una.cr

2 irene.hernandez.ruiz@una.cr
} 
In this regard, Mata et al (2016) have proposed the development of an electronic commerce system to allow the direct sale of roasted coffee from producers to consumers as a solution to the coffee paradox. This mechanism would eliminate intermediaries in the global value chain of coffee, making it possible to producers to receive the price paid for roasted coffee by the final consumers.

This system is envisioned as an innovative tool to promote social and economic change, and it is being developed and implemented by the Universidad Nacional (UNA) in Costa Rica (http://www.una.ac.cr ).

In the following sections, we discuss the background, and the design and development considerations for this e-commerce system, known as crgourmetcoffee.com (https://www.crgourmetcoffee.com). In addition, we present the results of this project to date and the further steps being taken to convert the existing prototype into a fully operational e-commerce platform.

\section{BACKGROUND}

\subsection{The Coffee Paradox}

The coffee paradox has been studied by Daviron and Ponte (2005) and Fitter and Kaplinsky (2001a, 2001b). This phenomenon is characterized by the increasingly lower prices that farmers receive for their coffee, even though the demand for this product has been growing. This is due to the entry of new countries in coffee production - such as, Vietnam, Indonesia and Uganda-, which has increased the world production of this product. Currently, around 70 countries -more than a third of the existing in the world- produce coffee (ICO, 2014).

In this regard, it is important to note that most of the coffee consumed in the world behaves as a primary commodity -for which the quality of the product is not adequately recognized ${ }^{3}$. For this reason, coffee roasters can modify the mix of beans they use in order to produce their roasted coffee products, taking advantage of the price obtained from different countries (Daviron and Ponte, 2005).

However, with the advent of specialty coffee -which differs by flavor (gourmet coffee), origin (coffee with denomination of origin) or process (organic coffee, trade-fair coffee, etc.)- possibilities are arising for the de-commodification of this product, providing options to cope with the coffee paradox (Kaplinsky and Fitter, 2004).

\subsection{The Global Value Chain (GVC) for Coffee}

As Mata et al (2016) claim, the structure of the global value chain (GVC) for the mainstream-coffee market is greatly responsible for the coffee paradox. Seven major actors can be identified in this chain: farmers, processors, export agents, global traders, roasters, retailers, and consumers (see Figure 1).

Coffee farmers in developing countries grow coffee trees, which produce coffee cherries. After being harvested, the coffee cherries need to be processed to separate the beans from the skin and pulp and reduce their humidity. This process produces what is referred to as "green coffee" and is usually done in large processing plants. Since small farmers commonly do not count with such facilities ${ }^{4}$, they sell their harvested cherries to coffee processing plants. As a result of this processing, beans from different producers are mixed, losing the coffee its traceability to the producer.

Most of the green coffee produced is exported, although a small part remains in the producing country for local consumption (see Figure 1). This is due since green coffee lasts longer than roasted coffee. Exporting of green coffee is done through export agents, which act as intermediaries between the processing plants and the global traders and roasters in consuming countries. As already explained, roasters usually blend different types of green-coffee beans, prior to roasting them to release their aroma. Roasted coffee (ground or in whole bean) is later packed in vacuum-sealed bags, to be finally sold by retailers - mainly supermarkets- to consumers.

\footnotetext{
${ }^{3}$ Coffee sold under this condition is said to be traded in the mainstream market.

${ }^{4}$ However, some small farmers have begun to process their own coffee in micro-mills.
} 


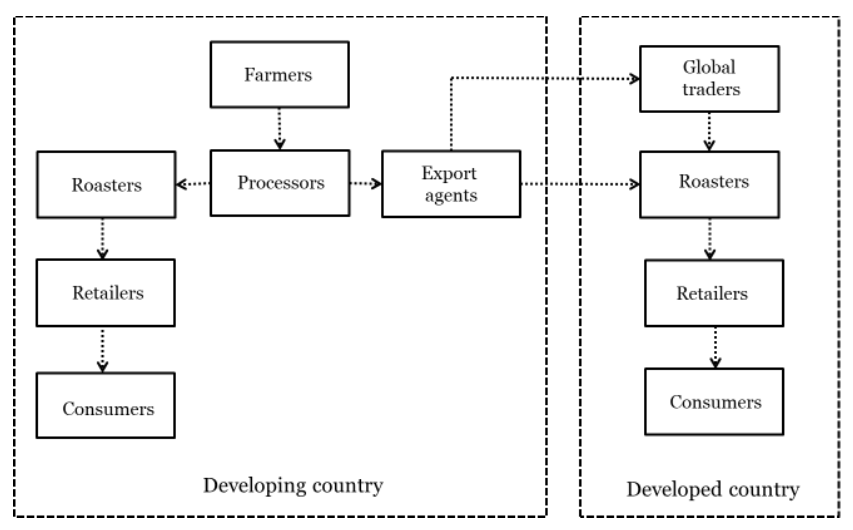

Figure 1. Global value chain for coffee (Mata et al, 2016)

The distribution of rents between actors in developing and developed countries regarding coffee has been a matter of discussion for long time (see Daviron and Ponte (2005), Fitter and Kaplinsky (2001a, 2001b), Kaplinsky and Fitter (2004) and Fairtrade Foundation (2012)). Although each of the activities in the GVC for coffee described before add value to the coffee purchased by the final consumers - and therefore, this value is reflected in the price paid by such consumers-, it is claimed that oligopolistic conditions existing in this chain allow international roasters to extract rents -that is, a compensation beyond the value-added. For this reason, coffee farmers are able to receive only 7 to 10 percent of the price paid by final consumers (ITC, 2011), even though it is widely recognized that the main determinants of coffee quality come from its cultivation and processing (species and variety of coffee cultivated, type of soil, altitude and climate of the plantation, and type of processing for the beans) (Brown, 1991) -that is, from value added by local, and not international, actors.

Furthermore, different from other agricultural products, it is the international roasters -and not the retailers, as usually occurs in other agriculture products- which enjoy a privileged position in the GVC for coffee (Daviron and Ponte, 2005). Therefore, the governance of this GVC - which relates to authority and power relationships among actors in the chain- rests on international roasters, particularly those with a large market share (e.g., Nestlé, Mondelēz -formerly Kraft Foods--, and Sara Lee Corp. (López Porras, 2014)).

\subsection{E-commerce Systems used to trade Coffee in Costa Rica}

As previously indicated, there are five intermediaries between coffee farmers in developing countries and final consumers in developed countries (processors, export agents, global traders, roasters, and retailers). In addition to the physical activities for production, processing and distribution that these intermediaries perform - previously discussed-, these actors also carry out informational functions aimed at matching buyers and sellers, facilitating the transactions, and providing institutional infrastructure (see the work of Bakos (1998) about these functions). This is because coffee farmers traditionally have not been able to perform these informational activities, due to lack of economies of scale, expertise, or contact networks (Mata et al, 2016). However, given the communication and brokerage effects of information and communication technologies (ICT) - postulated by Malone et al (1987) -, these technologies are able to reduce search costs and to handle complex products - as it is the case with gourmet coffee. Therefore, ICT can be used to overcome these limitations, favoring the creation of electronic markets. These effects are very well epitomized in modern e-commerce systems.

In the case of Costa Rica, Mata et al (2016) identified two electronic commerce systems used for trading coffee: 1) the Cup of Excellence and 2) the electronic commerce systems developed by Costa Rican roasters. Both systems support the de-commodification of coffee and focus on the sale of gourmet coffee.

The Cup of Excellence - already mentioned- has been developed by the Alliance for Coffee Excellence (https://allianceforcoffeeexcellence.org/), a not-for-profit organization aimed at rewarding quality in coffee. The system facilitates the direct sale of green coffee -through an electronic auction- from farmers in selected developing countries to international roasters. Therefore, this is a B2B e-commerce system.

Different from coffee offered in the mainstream market, this system offers coffee from a single farmer ("single-estate" coffee), allowing its traceability back to the producer. 
Although the Cup of Excellence can benefit coffee farmers - allowing them to obtain better prices, and thus mitigating the effect of the coffee paradox - its impact is very limited for at least two reasons. First, the system requires that farmers prepare samples of exceptional quality (known as micro-lots) -a process which is expensive for the farmers. Second, the coffee samples presented by farmers need to be cupped several times by experts to assess their quality -which is cumbersome. For these reasons, the number of coffee farmers that can benefit from the Cup of Excellence is reduced, and the quantities of coffee that can obtain higher prices thanks to this system are minimal. Furthermore, there is evidence that although farmers can obtain higher prices, international roasters can get even higher prices from selling the award-winning coffees (Daviron and Ponte, 2005).

The limited scope of the Cup of Excellence to mitigate the coffee paradox can be explained using the analysis of GVCs (see the seminal work on this field by Gereffi et al (1994)), since this system does not change the geographical location of the agents in the GVC for coffee (territoriality), neither does it change the authority and the power relations between the actors involved in this chain (governance) (Mata et al, 2016).

The other e-commerce systems found in Costa Rica to trade coffee are the systems developed by Costa Rican roasters. Different from the Cup pf Excellence, these are B2C systems. Mata and Quesada (2015) found that almost 30 percent of the roasters in Costa Rica had developed such systems and that most of them are intended to sell roasted coffee abroad. Although such systems can benefit Costa Rican roasters by obtaining higher prices, this advantage does not necessarily is transferred to the farmers. By allowing domestic roasters to sell roasted coffee directly to final consumers in developed countries, this type of systems displace roasters in developed countries - upgrading the first their position in the GVC for coffee-, and thus, letting the roasters in developing countries to reach the same advantageous situation that their homologous, in developed countries, have. Therefore, although this second type of system allows a change in territoriality in the GVC, governance in this chain remain the same (Mata et al, 2016).

As a result of the above, Mata et al (2016) conclude that the key for an e-commerce system to address the coffee paradox rests in its ability to establish a direct connection between coffee farmers and consumers. This is supported by Pelupessy's (2001) remark that at present there is not a market that allows these two actors to relate. Due to the structure of GVC for coffee, consumers connect with roasters in a "roasted-coffee market", whereas farmers deal with roasters in a "green-coffee market" (see Figure 2), being roasters in developed countries the common denominator in both markets.

Furthermore, roasters tend to make farmers invisible to consumers. In part, this is due since in the mainstream-coffee market is not possible to trace the coffee beans back to their producers, serving the roasters as the guarantors of their quality. Therefore, Mata et al (2016) postulate that by including meaningful information on coffee farmers in an e-commerce system, consumers can relate better to their practices and endowments, which in the end influence the quality of coffee -as already explained.

Figure 2 shows the differences among the connections provided by the Cup of the Excellence, the Costa Rican roasters' e-commerce sites, and the proposed e-commerce system aimed to mitigate the coffee paradox in Costa Rica.

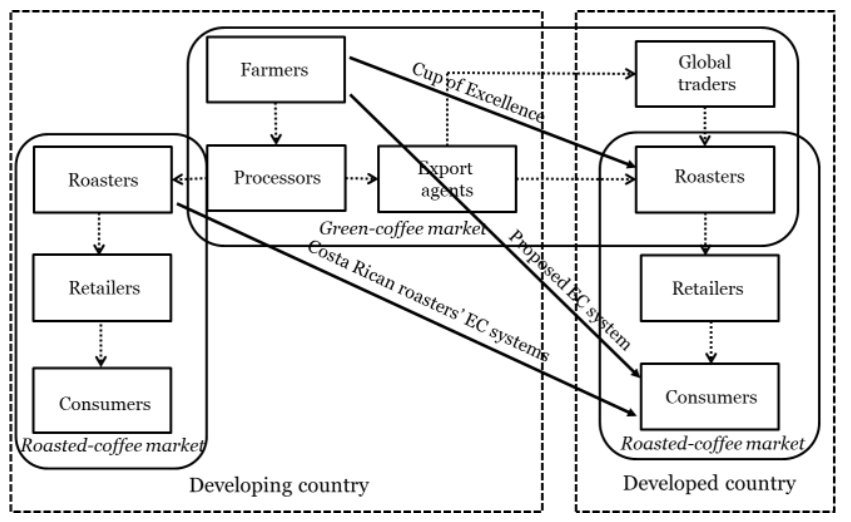

Figure 2. Connections for different e-commerce systems for coffee in Costa Rica 


\section{DESIGN AND DEVELOPMENT CONSIDERATIONS FOR CRGOURMETCOFFEE.COM}

\subsection{Methodology}

We started the design of crgroumentcoffee.com in the middle of 2016. At the beginning, we thought this system could be designed with the participation of the coffee farmers in Costa Rica, using a "design thinking" methodology (Brown and Wyatt, 2010). However, we early discovered that coffee producers in Costa Rica were not well versed in e-commerce. Therefore, we switched the design approach to one based on benchmarking. In this regard, we considered e-commerce sites belonging to the following three categories: 1) international roasting companies, 2) Costa Rican roasters, and 3) Costa Rican farmers.

\subsubsection{E-commerce Sites from International Roasters}

Although most international large coffee roasters have websites for their coffee brands ${ }^{5}$, they are mainly informational -not transactional- sites. This is because these roasters are large consumer product companies, which rely on retailers to sell their products to final consumers. Other specialized roasters, however, have e-commerce sites. Among them, the site of Intelligentsia (https://www.intelligentsiacoffee.com) - a company selling specialty coffee- proved to be useful. This site provides information for farmers, whose coffee is sold through the site. Nevertheless, despite this company promotes coffee from selected coffee farmers worldwide (single-estate coffee), it acts as an intermediary selling the coffee "on behalf" of the producers. That is, it buys green coffee from selected coffee farmers, roast it and sell the resulting product through e-commerce.

\subsubsection{E-commerce Sites from Costa Rican Roasters}

As previously mentioned, many Costa Rican roasters have developed e-commerce systems to sell their roasted coffee. These systems barely mention coffee farmers. The most successful of such systems is the one operated by Café Britt (https://www.cafebritt.com), owned by Grupo Britt -a multinational company based in Costa Rica (Mata and Quesada, 2015). This site does not only sell Costa Rican coffee, but also coffee from Colombia and Peru.

\subsubsection{E-commerce Sites from Costa Rican Farmers}

A handful of Costa Rican farmers have developed e-commerce site to sell their own roasted coffee. Among them, we found interesting the following sites: Brumas del Zurquí (https://www.cafebrumasdelzurqui.cr) and Monte Copey (https://montecopeycoffee.com) - both owned by farmers highly ranked in previous editions of the Cup of Excellence of Costa Rica. Although, these sites have merits, they have several limitations. First, it is difficult for these sites to position themselves on the Internet based on search engine criteria. Second, these sites offer a reduced number of products, which are limited to the available coffee varieties grown by the respective farmers. Finally, although the sites are owned by the same farmers, the amount of information provided about them is very scarce, which does not allow these sites to establish a meaningful connection with final consumers. The first two limitations are related to the need of developing a national platform to facilitate marketing and promotion of roasted coffee in Costa Rica, as proposed by López Porras (2014).

\subsection{Site Structure}

The site for crgourmetcoffee.com has been designed as an electronic platform, consisting of different webstores, having them front-stores for each farm owned by a participating famer, and a corresponding back-store for this farmer. The store-fronts are public and have a catalog of roasted coffee products and offer all the expected e-commerce functionality. In addition, there is a general administration module used to enable and disable webstores and control the operation of the platform (see Figure 3 ).

\footnotetext{
${ }^{5}$ See for example htttp://www.nescafe.com part of Nestlé and http://www.jacobsdouweegberts.com part of Mondelēz.
} 


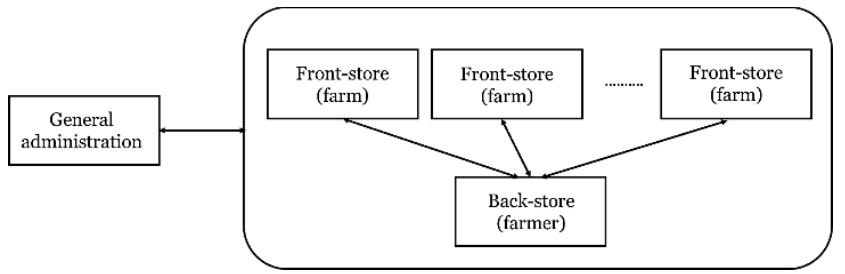

Figure 3. Site structure for crgourmetcoffee.com

\subsection{Graphic Design}

Several iterations were used to come to the graphic design for crgourmetcoffee.com. The following criteria were used for this design: 1) a minimalist approach, 2) use of colors and images related to coffee ${ }^{6}$, and 3) styles for the pages able to be displayed responsively in different devices (desktops, tablets, and mobile phones). Figure 4 shows the design of the homepage for the site.

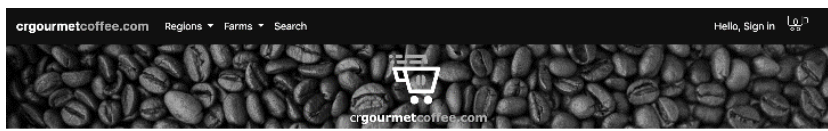

Featured products
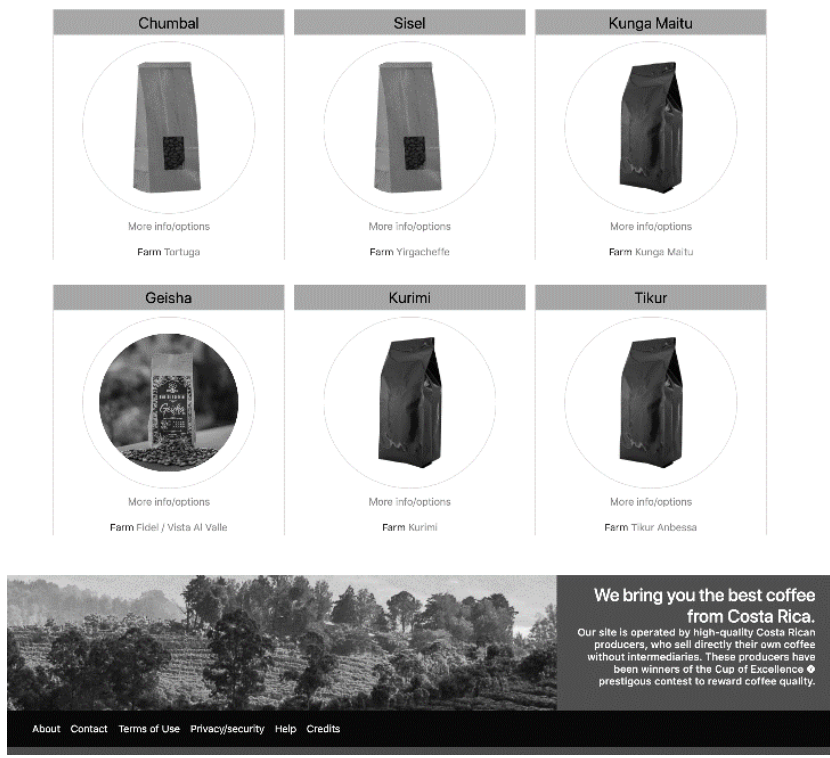

Figure 4. Graphic design for crgourmetcoffee.com (homepage)

\subsection{Farm Information}

In order to achieve an effective communication between farmers and users (potential consumers), a page with information about the farm and its products have been developed (see Figure 5). This page will be complemented with a page containing information about the famer, which is currently being designed.

It is important that most coffee farms in Costa Rica are owned by families, which have been inherited through several generations. This situation lends to the use of storytelling to connect the consumer to the farmer. Storytelling has been proposed as useful way for marketing (see Woodside et al (2008)). Following Picard's (1997) influential work, we plan to use affective computing -that is, "computing that relates to,

\footnotetext{
${ }^{6}$ These colors cannot be appreciated in the figures, since they are presented in black and white.
} 
arises from, or deliberately influences emotions (p. 3) - to develop the page with information about the farmer. Storytelling and affective computing will support relationship marketing, which "is based on the notion that on top of the value of products and/or services that are exchanged, the existence of a relationship between two parties creates additional value for the customer and also for the supplier or service provider" (Grönroos, 2004, p. 99). Such type of marketing has been proposed by Daviron and Ponte (2005) for coffee in the form of "relational coffee", or coffees for which consumers establish a direct relationship with actors in coffee-producing countries. This marketing strategy has been successfully used by Café Britt in Costa Rica (Mata and Quesada, 2015).

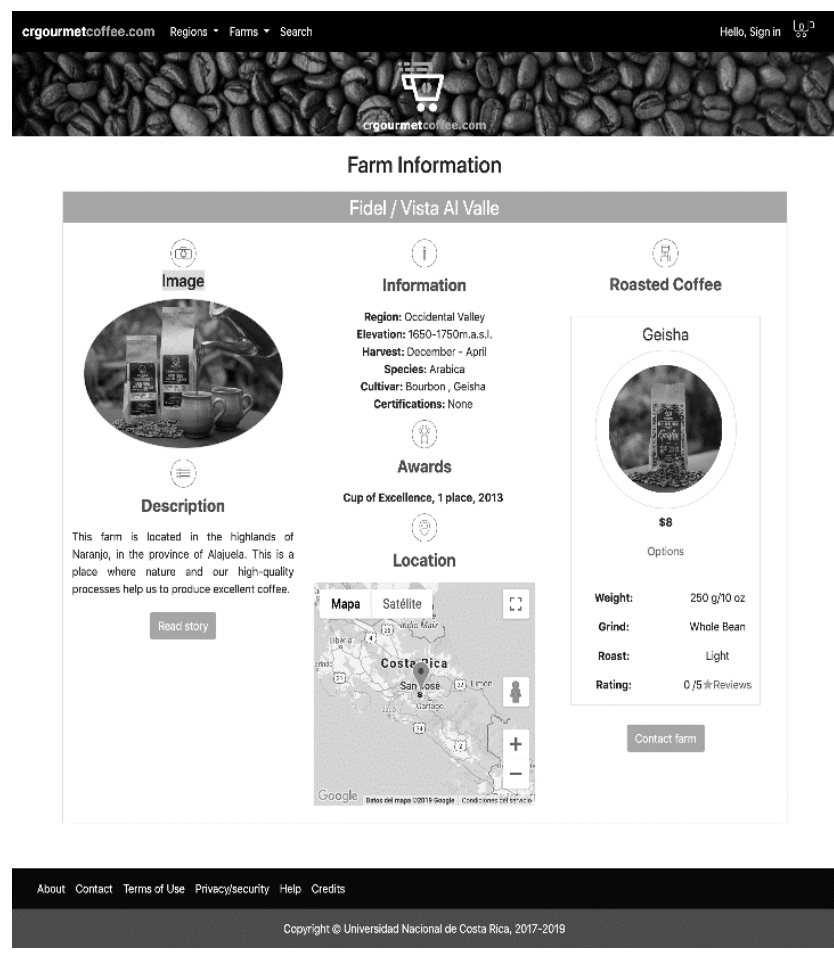

Figure 5. Example of the information for a farm

\subsection{Software Considerations}

A LAMP ${ }^{7}$ software stack has been used to develop crgourmetcoffee.com. We originally planned to use an open-source e-commerce package based on PHP to develop the site. For this purpose, we considered the following options: Drupal/Ubercart (https://www.drupal.org/project/ubercart), Magento (https://magento.com/), osCommerce (https://www.oscommerce.com/), and Zen Cart (https://www.zen-cart.com/). However, only Drupal/Ubercart offered a free multi-vendor solution, by adding a module known as Ubercart Marketplace (https://www.drupal.org/project/ubercart_marketplace).

After reviewing this last solution, we found it difficult to implement with this package the functionality required for the proposed site for two reasons. First, although Ubercart Marketplace allows different vendors to manage their own products, all the products appear in the same webstore. Second this package is designed so all payments go to the operator of the site, and not directly to the different vendors. We considered important to separate the technical operation of the site from its financial procedures, to isolate the operator of the site from possible legal disputes that may arise from the transactions being executed, as later discussed.

Changing the code for Drupal/Ubercart Marketplace to create different webstores for farmers and allow producers to receive directly their own payments was deemed more difficult than to develop the system from

\footnotetext{
${ }^{7}$ Linux (operating system), Apache (web server), MySQL (database management system), PHP (programming language).
} 
scratch. For this reason, we selected Symfony (https://symfony.com) -a PHP-based framework implementing the model-view-controller architectural pattern- to develop the e-commerce site.

In addition, we used the bootstrap front-end framework (https://getbootstrap.com), to make the site responsive. This eliminates the need to have apps for using it with mobile devices.

\section{RESULTS TO DATE}

We have successfully completed a prototype for crgourmetcoffee.com. A usability test of this site was conducted in November 2018, using the System Usability Scale (SUS) (Brooke, 2013) and relying on professors and students at UNA. This test provided encouraging results, as well as suggestions for further improvement of the system.

We also have presented the prototype to several coffee farmers in Costa Rica, who have expressed much interest in using it. According to them, the fact that this system provides the opportunity to create a national platform to market and sell gourmet coffee is a major advantage, since it simplifies its use - not having the farmers to deal with technical aspects-, as well as it provides better opportunities to position the site on the Internet.

Terms of use for the system are being developed, as well as security and privacy policies, for the platform. Such policies consider the General Data Protection Regulation (GDPR), approved by the European Union (EU, 2018).

Furthermore, contractual terms with the Costa Rican farmers -that will be using crgourmetcoffee.comare been finalized. In this contractual agreement, UNA legally will be only the facilitator of the platform. This means that the university will not be responsible for any of the transactions occurring through the platform.

\section{FURTHER STEPS AND MAJOR CHALLENGES}

We are in the process of making the prototype for crgourmetcoffee.com into an operational e-commerce platform. In this endeavor, we are offering crgourmetcoffee.com to selected coffee farmers -that have been highly ranked in the previous editions of the Cup of Excellence- without cost until the end of 2021. After that period, we will reevaluate the way the system will be provided. At the long term, the ideal will be to license the software to an "association" of gourmet-coffee producers. Although, this association does not exist, we believe crgourmetcoffee.com could lead the way for creating it.

For implementing crgourmetcoffee.com, we are in the process of seeking the collaboration from key government agencies in Costa Rica, such as the Ministry of Science, Technology and Telecommunications (MICITT), the Ministry of Agriculture and Livestock (MAG), the Ministry of Foreign Trade (COMEX), the Export Promoting Agency of Costa Rica (PROCOMER) and the Coffee Institute of Costa Rica (ICAFE). These organizations are key to develop a national platform for trading roasted coffee.

We are also looking for funding for this project. Although, most of the labor and operational costs needed to launch this platform are being covered by UNA, additional funding will be instrumental to promote the platform on Internet and to improve the farmers' capabilities to sell roasted coffee.

In order to provide a consistent framework for handling payments and providing the necessary logistics services, we are in the process of selecting a company to provide the electronic-payment services and another to offer the shipping services needed for this system. Logistics is a major challenge for a platform like this, since shipping many small orders -as it is necessary in B2C- is a complex and expensive process (Turban et al, 2012). Furthermore, coffee farmers are accustomed to export green coffee -which is a large volume process-, therefore, selling small packages of roasted coffee will demand farmers to develop new processes and skills.

Training coffee farmers to use the system and operate its back-store facility also presents challenges, since many of them are not well acquainted with IT. However, we have found that children of such producers are very knowledgeable in IT -some of them even have university education. Therefore, training efforts will focus on this group. 
Finally, securing the quality of the coffee sold through the system is paramount. Coffee quality is guaranteed by two basic mechanisms: organoleptic and non-organoleptic (Daviron and Ponte, 2005). Organoleptic mechanisms rely on the human senses, and they are associated with coffee characteristics such as acidity, aroma, body and taste. For this purpose, coffee samples are cupped by experts and assessed based on such characteristics (ITC, 2011). This is a cumbersome and expensive mechanism, which is used in the Cup of Excellence. On the other hand, non-organoleptic mechanisms rely on subjective attributes of coffee. The most commonly used of such mechanisms is the creation of brands, which is mainly used by roasters. International roasters invest heavily in advertisement related to their brands, for example, Nescafé, Folgers, and Maxwell House.

A combination of both mechanisms is planned to be used in crgourmetcoffee.com. In this regard, the system will be offered only to farmers that have been ranked as producers of specialty coffee by the Cup of Excellence of Costa Rica. This guarantees that the participating farmers have already the endowments (coffee trees, agro-climatic conditions, etc.) and knowledge about coffee cultivation, harvesting and processing to produce high-quality coffee. Furthermore, through marketing methods -such as relationship marketing, previously mentioned- and the name that Costa Rican coffee has worldwide, we plan to create a reputation for the platform. Creating such a reputation will overcome the limitation of positioning on the Internet individual farmers' websites -as already mentioned-, since participating farmers would be able to rent the reputation from the platform (see the pioneering work on economics of e-commerce by Choi et al (1997)). This last mechanism (reputation) will be complemented by a rating system for each of the coffee products offered through crgourmetcoffee.com, which is currently under development.

\section{CONCLUSION}

Although e-commerce is growing in Costa Rica, as in most Latin American countries (Visa, 2016), this growth is mainly due to the use of foreign platforms, such as Amazon, E-Bay or AliExpress. In addition, most

e-commerce efforts in the country has focused on creating sites for the local market; however, the reduced size of the country (roughly 5 million inhabitants) makes this market off-putting.

Instead of thinking inwards, efforts to develop e-commerce sites in Costa Rica should look abroad. In this process, using products where Costa Rica has a competitive advantage -such as coffee- is key. Cafe Britt, as already mentioned, illustrates well this approach. According to Mata and Quesada (2015), this company sold approximately 18 percent of its coffee through e-commerce in 2013.

The platform crgourmetcoffee.com is been designed and developed with this principle in mind: focus on the foreign market with coffee, a product in which Costa Rica excels. In this way, this platform is aimed at mitigating the coffee paradox, and thus encourage Costa Rican farmers that produce gourmet coffee to continue in the business.

Furthermore, we believe this platform might encourage new generations to get involved in the coffee activities of their parents, favoring to pass down the coffee tradition and knowledge from generation to generation. Adding a technological component to coffee production and marketing can make it more attractive to the farmers' children to get involved in the coffee activities of their families.

Although crgourmetcoffee.com has the potential to become a tool for social and economic change, still several challenges must be faced -as previously discussed- to achieve this purpose.

\section{REFERENCES}

Bakos, Y., 1998. The Emerging Role of Electronic Marketplaces on the Internet. In Communications of the ACM, Vol. 41, No. 8, pp. 35-42.

Brooke, J., 2013. SUS: A Retrospective. In Journal of Usability Studies, Vol. 8, No. 2, pp. 29-40.

Brown, J.G., 1991. Agro-Industry Profiles: Coffee. World Bank,Washington, DC, USA.

Brown, T. and Wyatt, J., 2010. Design Thinking for Social Innovation. In Development Outreach, Vol. 12, No. 1, pp. 29-43.

Choi, S. et al, 1997. The Economics of Electronic Commerce. Macmillan Computer Publishing, Indianapolis, IN, USA. 
Daviron, B and Ponte, S. 2005. The Coffee Paradox: Global Markets, Commodity Trade and the Elusive Promise of Development. Zed Books, London, UK.

EU, 2018. Regulation (EU) 2016/679 of the European Parliament and of the Council of 27 April 2016 on the Protection of Natural Persons with Regard to the Processing of Personal Data and on the Free Movement of Such Data, and Pepealing Directive 95/46/EC (General Data Protection Regulation) [online]. Available at: https://eur-lex.europa.eu/legal-content/EN/TXT/PDF/?uri=CELEX:32016R0679\&from=EN.

Fitter, R. and Kaplinsky, R., 2001a. Can an Agricultural Commodity Be De-commodified, and If So Who Is to Gain? In IDS Bulletin (discussion paper 380). Institute of Development Studies, University of Sussex, Brighton, UK.

Fitter, R. and Kaplinsky, R., 2001b. Who Gains from Product Rents as the Coffee Market Becomes More Differentiated?: A Value-Chain Analysis. In IDS Bulletin, Vol. 32, No. 3, pp. 69-82.

Fairtrade Foundation, 2012. Fairtrade and Coffee. Fairtrade Foundation, London, UK.

Gereffi, G. K. et al, 1994. Introduction: Global Commodity Chains. In Gereffi G. and Korzeniewicz, M. (eds.). Commodity Chains and Global Capitalism. Praeger Publishers, Westport, CT, USA.

Grönroos, C., 2004. The Relationship Marketing Process: Communication, Interaction, Dialogue, Value. In Journal of Business \& Industrial Marketing, Vol. 19, No. 2, pp. 99-113.

ICAFE, 2017. Informe sobre la Actividad Cafetalera en Costa Rica. Instituto del Café de Costa Rica, San José, Costa Rica.

ICO, 2014. Exports of All Forms of Coffee to Exporting Countries: Calendar Years 2000 to 2013. International Coffee Organization, London, UK.

ITC, 2011. The Coffee Exporter's Guide. 3rd ed.. International Trade Centre, Geneva, Switzerland.

Kaplinsky, R. and Fitter R., 2004. Technology and Globalisation: Who Gains when Commodities Are De-commodified? In International. Journal of Technology and Globalisation, Vol 1, No. 1, pp. 5-28.

López Porras, K., 2014. El Mercado Mundial de Café Tostado. Promotora del Comercio Exterior de Costa Rica, San José, Costa Rica.

Malone, T.W., Yates, J. and Benjamin, R.I,, 1987. Electronic Markets and Electronic Hierarchies. In Communications of the ACM, Vol. 30, No. 6, pp. 484-497.

Mata, F. J. and Quesada, A., 2015. E-Commerce and Coffee in Costa Rica: Case Studies of Costa Rican Roaster Companies. Proceeding of the 2015 Latin American Computing Conference (CLEI) [online]. Avaliable at https://doi.org/10.1109/CLEI.2015.7359997.

Mata, F.J., Quesada, A., and Mata-Marín, G., 2016. Can E-commerce Provide a Solution to the Coffee Paradox?: The Case of Costa Rica. In Mata, F.J. and Pont, A. (eds). ICT for Promoting Human Development and Protecting the Environment. Springer International Publishing, Switzerland.

Otey, J., 2018. "Café de Costa Rica Rompió Récord de Precios", CrHoy, 10 July [online]. Available at: https://www.crhoy.com/economia/cafe-de-costa-rica-rompio-record-mundial-de-precios/.

Pelupessy, W., 2001. La Crisis de Mercado en Cadenas Globales del Café. In Perspectivas Rurales, Vol. 5, No. 1, pp. 57-71.

Picard, R., 1997. Affective Computing. MIT Press, Boston, MA., USA.

PROCOMER, 2017. Anuario estadístico 2016. Promotora de Comercio Exterior de Costa Rica, San José, Costa Rica [online] Available at: https://procomer.com/downloads/estudios/estudio_estadistico_2016/Capitulo3.pdf.

Turban, E., King, D., Lee, J., Liang, T. and Turban, D., 2012. Electronic Commerce 2012. New Jersey: Pearson Education, Upper Saddle River, NJ, USA.

Visa, 2016. Latin America e-Readiness Report by Visa. Visa [online]. Available at: https://www.visa.com.bs/pay-withvisa/ereadiness.html.

Woodside, A., Sood, S., and Miller, K.E., 2008. When Consumers and Brands Talk: Storytelling Theory and Research in Psychology and Marketing. In Psychology \& Marketing, Vol 25, No 2, pp. 97-145. 